\title{
Phase lead/lag due to degree inhomogeneity in complex oscillator network with application to brain networks
}

Junhyeok Kim", Joon-Young Moon², Uncheol Lee ${ }^{2,3}$, George A Mashour ${ }^{2,3}$, Seunghwan Kim', Tae-Wook Ko ${ }^{4^{*}}$

From 24th Annual Computational Neuroscience Meeting: CNS*2015

Prague, Czech Republic. 18-23 July 2015

Brain anatomical connectivity is one of the main factors influencing information flow among the brain areas [1] and phase lead/lag relationship between oscillations of brain areas is known to be related to the information flow $[2,3]$. In this study, we analyze the network effect on the phases of coupled oscillators using Kuramoto model and obtain analytical relationship between phase lead/lag and degrees of network nodes. We also show robustness under various conditions, improving upon the result of ref. [4]. Using the brain anatomical connectivity and the relationship, we can explain the phase distribution across the brain. At first, we investigate the relationship in the

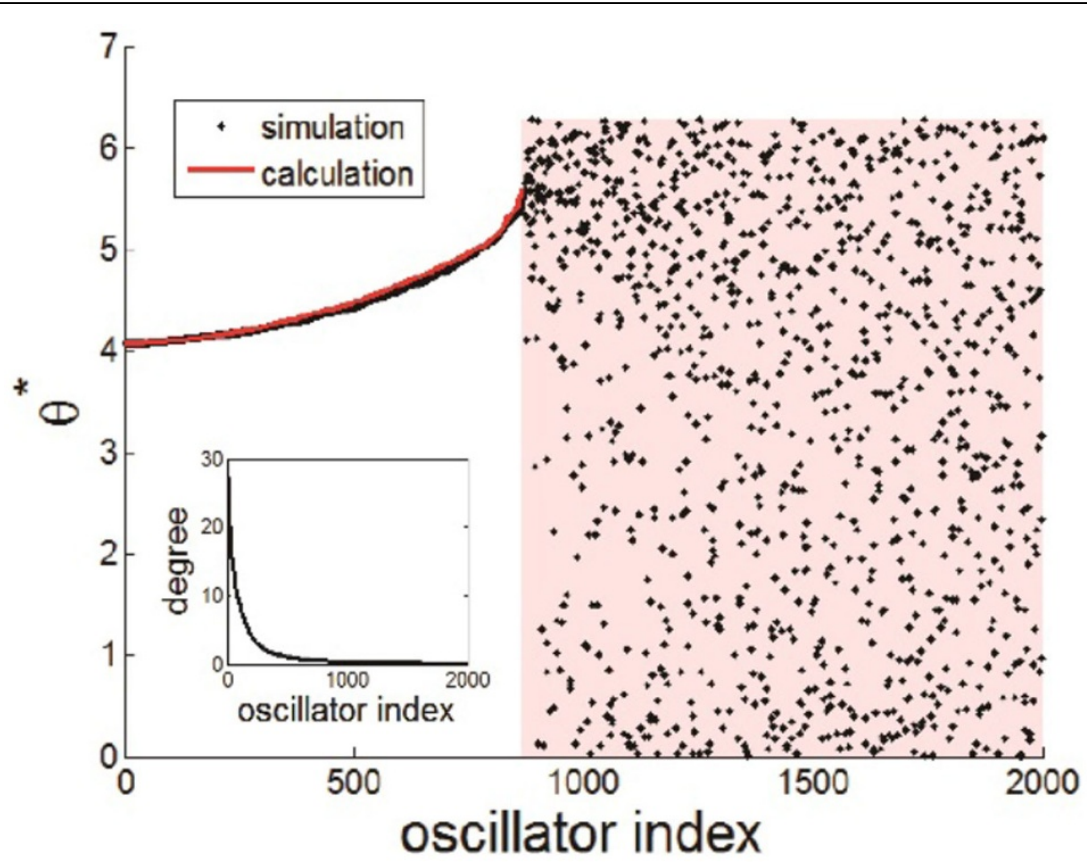

Figure 1 The phase (black dots) of each oscillator and the calculated phases (red line) from analytic derivation. They match well in locked region and red shaded area represents drifting region. The inset shows the degree for each node.

\footnotetext{
* Correspondence: twko@nims.re.kr

${ }^{4}$ National Institute for Mathematical Sciences, Daejeon 305-811, Republic of Korea

Full list of author information is available at the end of the article
} 
oscillator model on a scale-free network of which degree distribution follows a power law [5]. Confirming the result of previous study [4], the phases of higher degree nodes lag the phases of lower degree nodes. Similar behaviors are observed also in random network, where the degree distribution follows a Poisson distribution. Using mean-field approximation, we analytically derive the relationship between phases and node degrees as shown in Figure 1. With various conditions of time delay and coupling strength, we also observe that this phase lead/lag relationship between nodes is robust. Our exact relationship can be well applied to human brain anatomical networks.

\section{Authors' details}

'Nonlinear and Complex Systems Laboratory, Department of Physics, Pohang University of Science and Technology, Pohang 790-784, Republic of Korea. ${ }^{2}$ Department of Anesthesiology, University of Michigan Medical School, Ann Arbor, MI 48109, USA. ${ }^{3}$ Center for Consciousness Science, University of Michigan Medical School, Ann Arbor, Ml 48109, USA. ${ }^{4}$ National Institute for Mathematical Sciences, Daejeon 305-811, Republic of Korea.

Published: 18 December 2015

\section{References}

1. Stam CJ, van Straaten EC: Go with the flow: use of a directed phase lag index (dPLI) to characterize patterns of phase relations in a large-scale model of brain dynamics. Neuroimage 2012, 62:1415-1428.

2. Rabinovich MI, Afraimovich VS, Bick C, Varona P: Information flow dynamics in the brain. Phys Life Rev 2012, 9:51-73.

3. Akam T, Kullmann DM: Oscillatory multiplexing of population codes for selective communication in the mammalian brain. Nat Rev Neurosci 2014, 15:111-122.

4. Moon J-Y, Lee UC, Blain-Moraes S, Mashour GA: General relationship of global topology, local dynamics, and information flow in simulated and empirical brain networks. PLOS Comp Biol 2015, (to be published).

5. Ko T-W, Ermentrout GB: Partially locked states in coupled oscillators due to inhomogeneous coupling. Phys Rev E 2008, 78:016203.

doi:10.1186/1471-2202-16-S1-P127

Cite this article as: Kim et al:: Phase lead/lag due to degree inhomogeneity in complex oscillator network with application to brain networks. BMC Neuroscience 2015 16(Suppl 1):P127.

\section{Submit your next manuscript to BioMed Central} and take full advantage of:

- Convenient online submission

- Thorough peer review

- No space constraints or color figure charges

- Immediate publication on acceptance

- Inclusion in PubMed, CAS, Scopus and Google Scholar

- Research which is freely available for redistribution

Submit your manuscript at www.biomedcentral.com/submit 